\title{
New In Vitro Coculture Model for Evaluating Intestinal Absorption of Different Lipid Nanocapsules
}

\author{
Norraseth Kaeokhamloed ${ }^{1}{ }^{\mathbb{D}}$, Emillie Roger ${ }^{1}$, Jérôme Béjaud ${ }^{1}$, Nolwenn Lautram ${ }^{1}$, Florence Manero ${ }^{2}$, \\ Rodolphe Perrot $^{2}$, Marie Briet ${ }^{3}\left(\mathbb{D}\right.$, Chadi Abbara $^{3}$ and Samuel Legeay $\left.1, * \mathbb{(}\right)$ \\ 1 MINT, INSERM U1066, CNRS UMR 6021, SFR ICAT, University of Angers, F-49000 Angers, France; \\ norraseth.kaeokhamloed@univ-angers.fr (N.K.); emilie.roger@univ-angers.fr (E.R.); \\ jerome.bejaud@univ-angers.fr (J.B.); nolwenn.lautram@univ-angers.fr (N.L.) \\ 2 SCIAM, SFR ICAT, University of Angers, F-49000 Angers, France; florence.manero@univ-angers.fr (F.M.); \\ rodolphe.perrot@univ-angers.fr (R.P.) \\ 3 Laboratoire de Pharmacologie-Toxicologie, CRPV, Angers University Hospital Center, \\ F-49000 Angers, France; chadi.abbara@chu-angers.fr (C.A.); marie.briet@chu-angers.fr (M.B.) \\ * Correspondence: samuel.legeay@univ-angers.fr
}

check for updates

Citation: Kaeokhamloed, N.; Roger, E.; Béjaud, J.; Lautram, N.; Manero, F.; Perrot, R.; Abbara, C.; Briet, M.;

Legeay, S. New In Vitro Coculture Model for Evaluating Intestinal Absorption of Different Lipid Nanocapsules. Pharmaceutics 2021, 13, 595. https://doi.org/10.3390/ pharmaceutics13050595

Academic Editor: Ana Beloqui García

Received: 6 April 2021

Accepted: 20 April 2021

Published: 21 April 2021

Publisher's Note: MDPI stays neutral with regard to jurisdictional claims in published maps and institutional affiliations.

Copyright: (c) 2021 by the authors. Licensee MDPI, Basel, Switzerland. This article is an open access article distributed under the terms and conditions of the Creative Commons Attribution (CC BY) license (https:// creativecommons.org/licenses/by/ $4.0 /)$.

\begin{abstract}
Standard models used for evaluating the absorption of nanoparticles like Caco-2 ignore the presence of vascular endothelium, which is a part of the intestinal multi-layered barrier structure. Therefore, a coculture between the Caco-2 epithelium and HMEC-1 (Human Microvascular Endothelial Cell type 1) on a Transwell ${ }^{\circledR}$ insert has been developed. The model has been validated for (a) membrane morphology by transmission electron microscope (TEM); (b) ZO-1 and $\beta$-catenin expression by immunoassay; (c) membrane integrity by trans-epithelial electrical resistance (TEER) measurement; and (d) apparent permeability of drugs from different biopharmaceutical classification system (BCS) classes. Lipid nanocapsules (LNCs) were formulated with different sizes (55 and $85 \mathrm{~nm}$ ) and surface modifications (DSPE-mPEG (2000) and stearylamine). Nanocapsule integrity and particle concentration were monitored using the Förster resonance energy transfer (FRET) technique. The result showed that surface modification by DSPE-mPEG (2000) increased the absorption of 55-nm LNCs in the coculture model but not in the Caco-2. Summarily, the coculture model was validated as a tool for evaluating the intestinal absorption of drugs and nanoparticles. The new coculture model has a different LNCs absorption mechanism suggesting the importance of intestinal endothelium and reveals that the surface modification of LNCs can modify the in vitro oral absorption.
\end{abstract}

Keywords: intestinal absorption; Caco-2; HMEC-1; apparent permeability; lipid nanocapsule; förster resonance energy transfer

\section{Introduction}

Drug administration by the oral route is considered the most accepted one by patients for drug delivery due to its convenience. However, some drugs present a low oral bioavailability due to low drug solubility or low intestinal permeability. This low permeability can be explained by the intestine's complex multilayer structure, consisting of the mucus barrier, the enterocytic barrier, and the endothelial barrier [1-3]. To improve oral drug delivery, drug encapsulation into nanocarriers, such as lipid nanocapsules (LNCs), is currently one of the most promising technologies. LNCs consist of an oily core enclosed by a shell of pegylated surfactant and phosphatidylcholine and can be prepared by a well-known lowenergy emulsification process: The phase-inversion temperature method [4,5]. LNCs have sizes ranging from 20 to $100 \mathrm{~nm}$ and can also be prepared with different surface-chemistry. For example, anionic LNCs can be produced by the addition of DSPE-mPEG (2000) [6] and cationic LNCs by adding stearylamine [7] or chitosan [8,9]. Previous studies demonstrated that LNCs enhance the in vivo oral bioavailability of paclitaxel, fondaparinux, albendazole, and praziquantel; and the in vitro intestinal absorption of paclitaxel, Sn38, decitabine, 
acyclovir, and efavirenz [7,10-16]. In addition, the use of the in vitro Caco-2 model allowed us to describe that LNCs are mainly transported via active endocytosis, or more precisely, through clathrin-dependent and caveolae-dependent transport mechanisms. Recently, the application of the Förster resonance energy transfer (FRET) technique coupled with Nanoparticle Tracking Analysis (NTA) demonstrated that few LNCs (around $0.3 \%$ of the initial quantity of LNCs) were able to be transported intact by transcytosis after passage through Caco-2 cell monolayer [17].

FRET is a useful technique to monitor the integrity of nanoparticles. It is based on the interaction between two spatially closed $(1-10 \mathrm{~nm})$ fluorophores in which the emission spectrum of the FRET-donor overlaps with the excitation spectrum of the FRETacceptor. The efficacy of the energy transfer between the two fluorophores is related to their proximity [18-20]. Thus, the loss of FRET-nanoparticles integrity will cause the FRET fluorophores to be released into the external medium and disperse, widening the fluorophores' proximity and resulting in the disappearance of the FRET-acceptor emission spectrum. As such, FRET is currently the only technique that can be used to follow the passage of intact nanoparticles in biological fluids or organisms. By a combination of the FRET technique with the NTA, Roger et al. developed a quantitative method to measure the particle concentration of intact LNCs [21], making this a precise tool for monitoring the membrane transport of nanocarriers.

Nevertheless, to date, the study on the membrane transport of LNCs across the intestinal barrier has been done only in the Caco-2 model, which consists of a monolayer of immortalized enterocyte cells cultivated on a semi-permeable membrane [22-25]. This model is the most commonly used and considered as a reference model for evaluating intestinal drug permeability. The Caco-2 model is used by regulatory agencies such as the USFDA (U.S. Food and Drug Administration) and the ICH (International Council for Harmonization) to establish the biopharmaceutics classification system (BCS) that classifies drugs based on permeability and solubility. The BCS classes can be defined by the apparent permeability $\left(\mathrm{P}_{\mathrm{app}}\right)$ of drugs in the Caco-2 model. Drugs with high permeability (class I and II) and low permeability (class III and IV) are defined by the $P_{\text {app }}>10 \times 10^{-6} \mathrm{~cm} / \mathrm{s}$ and $\mathrm{P}_{\text {app }}<2 \times 10^{-6} \mathrm{~cm} / \mathrm{s}$, respectively. Drugs with the $P_{\text {app }}$ between $2-10 \times 10^{-6} \mathrm{~cm} / \mathrm{s}$ are classified on a case-by-case basis because other pharmacokinetics parameters can influence their permeability [26-28]. Over the past few years, the Caco-2 model has been improved with other cell types added as a coculture system (e.g., HT-29, Raji-B coculture model) $[22,29,30]$. However, all these models for studying intestinal absorption ignore the endothelium layer that LNCs have to cross before reaching blood circulation. A recent study demonstrated that the intestinal endothelium plays a major role as a barrier against antigen and nutrients transport similar to the blood-brain barrier [31]. Another in vivo study in rats suggested that the disruption of the endothelium allows pathogens to enter the systemic circulation, strengthening the involvement of the intestinal endothelium in the mechanisms of oral absorption [32,33]. However, the role of intestinal endothelium in regulating drug absorption has never been studied. Besides, endothelium in other barriers such as the pulmonary endothelium (air-blood barrier) has been recently found to have a significant role in regulating the absorption of drugs and macromolecules [34]. Therefore, the role of the intestinal endothelium on drugs and nanoparticle absorption needs to be elucidated. Recently, Kasper et al. [35] developed an in vitro intestinal coculture model comprising Caco-2 and human hemangiosarcoma-derived endothelial cells (ISO-HAS1), but the model was used for studying the pathophysiology of the inflamed intestinal membrane, not for drug absorption. The objective of the present study is to develop and validate a new in vitro coculture model in order to systematically evaluate, for the first time, the transport of different LNCs across the intestinal epithelial-endothelial barrier.

In this context, we developed a new coculture model that can better mimic the gutblood barrier structure for studying the membrane transport of intact lipid nanocapsules. Caco-2 cells and Human Microvascular Endothelial Cell type 1 (HMEC-1) were seeded on the apical and basolateral side of the Transwell ${ }^{\circledR}$ plate, respectively. This model was 
characterized by membrane morphology, tight junction expression, and trans-epithelial electric resistance. Five different drugs were selected based on their physicochemical characteristics as a representation of drugs in general with different permeability and solubility according to the BCS [26-28]. Their permeability was evaluated in the coculture model in comparison with the reference Caco-2 model for the conformity with BCS. LNCs with different sizes (55 and $85 \mathrm{~nm}$ ) and different surface chemistries (DSPE-mPEG (2000) and stearylamine) were formulated and loaded with FRET dyes [35]. The transport of intact FRET-LNCs was investigated across the newly developed coculture compared to the well-established Caco-2 model, using the quantitative FRET fluorimetry technique coupled with the NTA to quantify the particle concentration of intact LNCs.

\section{Materials and Methods}

\subsection{Materials}

Caco-2 and HMEC-1 cells were obtained from American Type Culture Collection (Manassas, VA, USA). Sodium chloride, sodium tetraphenylborate, ethyl acetate, dichloromethane, methanol, triton $X-100$, Trizma ${ }^{\circledR}$ (base), anti- $\beta$-catenin rabbit mAb, anti-TJP1 (tight junction protein-1; a.k.a. ZO-1, zonula occludens-1) rabbit mAb, collagen type 1 (calf skin), 4',6-diamidino-2-phenylindole (DAPI), Dulbecco's modified Eagle's medium (DMEM D6429, with $4500 \mathrm{mg} / \mathrm{L}$ glucose, L-glutamine, sodium pyruvate, and sodium bicarbonate), dimethyl sulfoxide (DMSO), epidermal growth factor, hydrocortisone $\mathrm{HCl}$ powder for injection, Osmium tetroxide $\left(\mathrm{OsO}_{4}\right)$, Epon ${ }^{\mathrm{TM}} 812$ resin, metoprolol tartrate, propranolol $\mathrm{HCl}$, naproxen, atenolol and furosemide, and stearylamine were purchased from SigmaAldrich (Saint-Quentin Fallavier, France). Hank's balanced salted solution (HBSS), MCDB 131 medium (Gibco 10372-019), penicillin-streptomycin solution, goat anti-rabbit IgG Alexa Flour $^{\circledR}$ 488, DiI (1,10-dioctadecyl-3,3,30,30-tetramethyl-indocarbocyanine perchlorate), and $\mathrm{DiD}\left(1,1^{\prime}\right.$-dioctadecyl-3,3,3',3'-tetramethylindo-dicarbocyanine perchlorate) were purchased from Thermofisher (Villebon-sur-Yvette, France). Amphotericin B, Phosphatebuffered saline (PBS), and L-glutamine were purchased from PAA Laboratories (Toronto, ON, Canada). Fetal bovine serum (FBS) was purchased from Biowest (Nuaillé, France). Paraformaldehyde $32 \%$ and glutaraldehyde $25 \%$ were purchased from Electron Microscopy Science (Hatfield, PA, USA). Nonessential amino acid (NEAA) was purchased from Lonza (Verviers, Belgium). Ultrapure water was obtained from a Milli- $\mathrm{Q}^{\circledR}$ Advantage A10 System (Merck Millipore, Darmstadt, Germany). Costar ${ }^{\circledR}$ Transwell $^{\circledR}$ (12-well, polycarbonate membrane filters, $0.4 \mu \mathrm{m}$ pore size, $1.12 \mathrm{~cm}^{2}$ growth area) and T75 cell culture flasks were purchased from Costar (New York, NY, USA). Captex ${ }^{\circledR} 8000$ (glyceryl tricaprylate) was kindly provided by Abitec Corporation (Columbus, OH, USA). Lipoid ${ }^{\circledR}$ S75-3 (phosphatidylcholine and phosphatidylethanolamine mixture) was purchased from Lipoid GmbH (Steinhausen, Switzerland); Kolliphor ${ }^{\circledR}$ HS-15 (PEG 660 and polyethylene glycol 660 hydroxystearate mixture) from BASF (Ludwigshafen, Germany); and DSPE-mPEG(2000) (1,2-distearoyl-sn-glycero-3-phosphoethanolamine- $N$-[methoxy(polyethylene glycol)-2000] (ammonium salt)) from Avanti Polar Lipids (Alabaster, AL, USA).

\subsection{Caco-2 and HMEC-1 Cells Culture}

Caco-2 cells were cultured between passage 18 and 27 in DMEM medium supplemented with $20 \% v / v$ FBS, $1 \% v / v$ non-essential amino acids and $100 \mathrm{UI} / \mathrm{mL}$ penicillin, $0.5 \mathrm{mg} / \mathrm{mL}$ streptomycin. HMEC-1 cells were cultured between passage 4 and 12 in MCDB 131 medium supplemented with 10\% v/v FBS, $2 \mathrm{mM} / \mathrm{mL}$ L-glutamine, $100 \mathrm{UI} / \mathrm{mL}$ penicillin, $0.5 \mathrm{mg} / \mathrm{mL}$ streptomycin, $2.5 \mu \mathrm{g} / \mathrm{mL}$ amphotericin $\mathrm{B}, 1 \mu \mathrm{g} / \mathrm{mL}$ hydrocortisone, and $0.01 \mu \mathrm{g} / \mathrm{mL}$ epidermal growth factor. Cells were cultured in a T75 flask $\left(75 \mathrm{~cm}^{2}\right)$ and incubated at $37^{\circ} \mathrm{C}$ in humidified air with $5 \% \mathrm{CO}_{2}$.

\subsection{Caco-2/HMEC-1 Monoculture and Coculture on Transwell ${ }^{\circledR}$}

The polycarbonate membrane filters $\left(0.4 \mu \mathrm{m}\right.$ pore size, $1.12 \mathrm{~cm}^{2}$ growth area) in Transwell ${ }^{\circledR}$ inserts were coated with collagen type- 1 for $8 \mu \mathrm{g} / \mathrm{cm}^{2}$ on the apical side and 
$25 \mu \mathrm{g} / \mathrm{cm}^{2}$ on the basolateral side [28]. Caco- 2 cells $\left(1 \times 10^{5}\right.$ cells $)$ were seeded onto the apical side of the coated filter and cultured in DMEM medium, which was changed every 2-3 days. On day 18 , the Transwell ${ }^{\circledR}$ inserts were taken out, flipped upside down, and submerged under DMEM medium in a sterile basin with no bubbles trapped underneath the filter. Then, $5 \times 10^{4}$ HMEC- 1 cells were seeded onto the basolateral surface of the filter and were incubated for $2 \mathrm{~h}$ at room temperature. The inserts were then placed back into the Transwell ${ }^{\circledR}$ chambers. The Caco-2 media and the HMEC-1 media were filled in the upper chamber and the lower chamber, respectively, and were changed every two days. The coculture membranes were used on day 22 of Caco- 2 cells and day 4 of HMEC- 1 cells. Moreover, $1 \times 10^{5}$ Caco- 2 cells and $5 \times 10^{4}$ HMEC- 1 cells were separately seeded on the Transwell ${ }^{\circledR}$ inserts for the monoculture and then used as control.

\subsection{Membrane Morphology}

\subsubsection{Transmission Electron Microscopy (TEM)}

Caco-2/HMEC-1 cell membranes in Transwell ${ }^{\circledR}$ inserts were washed with HBSS and fixed with 2.5\% $v / v$ glutaraldehyde in phosphate buffer $\mathrm{pH} 7.4$ for $1 \mathrm{~h}$ at room temperature, then replaced with phosphate buffer $\mathrm{pH}$ 7.4. Afterward, $1 \% w / v \mathrm{OsO}_{4}$ was added to the cell samples and kept for $1 \mathrm{~h}$ at room temperature. Then, the samples were washed three times by deionized water and subsequently dehydrated by $50 \%, 70 \%$, and $95 \%$ ethanol twice and four times with 100\% ethanol. Next, the samples were embedded in Epon ${ }^{\mathrm{TM}} 812$ resin, which was left to polymerize for $24 \mathrm{~h}$ at $60^{\circ} \mathrm{C}$. Thin slices $(60 \mathrm{~nm})$ were cut from each sample using Leica UC7 ultramicrotome (Leica microsystems, Wetzlar, Germany) and deposited onto copper grids. The samples were stained with 3\% uranyl acetate in 50\% ethanol for $5 \mathrm{~min}$ and washed with deionized water. The samples were left to dry and then examined using the JEOL JEM-1400 electron microscope (JEOL, Tokyo, Japan).

\subsubsection{Confocal Fluorescence Microscopy}

Caco-2, HMEC-1, and Caco-2/HMEC-1 cell layers on Transwell ${ }^{\circledR}$ inserts were fixed for $20 \mathrm{~min}$ with $4 \% v / v$ paraformaldehyde at room temperature. The cells were washed three times with TBS and then permeabilized for $10 \mathrm{~min}$ with $0.5 \% \mathrm{v} / v$ Triton X-100 in TBS at room temperature. After washing out three times with TBS, $5 \% w / v$, FBS was added and rinsed out three times by TBS after $1 \mathrm{~h}$. Anti- $\beta$-catenin rabbit monoclonal antibodies $(\mathrm{mAb})$ $(1: 300$ in $2 \% w / v$ FBS in TBS) and Anti-ZO-1 rabbit mAb (1:300 in 2\% $w / v$ FBS in TBS) were separately added to the cells kept overnight at $4{ }^{\circ} \mathrm{C}$. Then cells were rinsed out three times by TBS, and the fluorescence-labeled secondary antibody goat anti-rabbit IgG Alexa Fluor ${ }^{\circledR}$ $488\left(1: 500\right.$ in $2 \% w / v$ FBS in TBS) was added and kept overnight at $4{ }^{\circ} \mathrm{C}$. Then, the cells were washed three times with TBS before stained with DAPI ( $3 \mu \mathrm{g} / \mathrm{mL}$ in TBS) for $10 \mathrm{~min}$ at room temperature. Finally, the filter membranes were cut from the Transwell ${ }^{\circledR}$ and mounted between microslides. The immunofluorescent staining images of cell confluency and tight junction structure were characterized by Leica TCS SP8 laser-scanning confocal microscope (Leica Microsystems, Heidelberg, Germany) with the excitation and emission wavelength of 488 and $520 \mathrm{~nm}$, respectively, for tight junction protein ZO-1 and adherens junction protein $\beta$-catenin, and $405 \mathrm{~nm}$ and $461 \mathrm{~nm}$, respectively, for cell nuclei. The software Leica Application Suite $\mathrm{X}$ was used for 3D visualization.

\subsubsection{Trans-Epithelial Electrical Resistance (TEER)}

TEER $\left(\Omega \cdot \mathrm{cm}^{2}\right)$ of the Caco-2 and the coculture cell layers were measured by the Millicell ${ }^{\circledR}$ ESR-2 volt-ohmmeter (Merck Millipore Corporation, Burlington, MA, USA) on days $4,11,18,21$, and 22 . The values were corrected by the resistance of blank Transwell ${ }^{\circledR}$ insert following the equation:

$$
\mathrm{TEER}=\left(\mathrm{R}_{\text {total }}-\mathrm{R}_{\text {blank }}\right) \times \mathrm{A}
$$

when $R_{\text {total }}$ is the measured resistance $(\Omega)$, $R_{\text {blank }}$ is the arithmetic mean of the resistance of blank Transwell ${ }^{\circledR}$ insert $(110 \Omega)$, and A is the area of Transwell ${ }^{\circledR}$ filter $\left(1.12 \mathrm{~cm}^{2}\right)$. 


\subsection{Transport Assay of the Free Drugs}

\subsubsection{Transport Assay Experiment}

Five reference drugs were chosen as a representation of drugs with different solubility and permeability according to the biopharmaceutical classification system (BCS) [36] (see Table 1). The drugs were firstly dissolved in ultrapure water (if necessary, methanol could be used to dissolve the drugs with the final concentration of methanol less than $0.02 \%$ $v / v$ ) and then serially diluted in HBSS to $5 \mu \mathrm{M}$. $1.5 \mathrm{~mL}$ of HBSS and $0.5 \mathrm{~mL}$ of diluted drug solutions were added to the basolateral and apical chambers of the Transwell ${ }^{\circledR}$ wells, respectively. Studies were performed on the Caco-2/HMEC-1 coculture model, the Caco2 model, the HMEC-1 model, and Transwell ${ }^{\circledR}$ without cells (control). The plates were incubated for $2 \mathrm{~h}$ at $37{ }^{\circ} \mathrm{C}$ with humidified air and $5 \% \mathrm{CO}_{2}$. Afterward, the apical and the basolateral media were collected and analyzed by HPLC-UV.

Table 1. Classification of the studied drugs according to the BCS.

\begin{tabular}{cccc}
\hline BCS Classes & Solubility & Permeability & Drugs \\
\hline I & High & High & Metoprolol tartrate, Propranolol HCl \\
II & Low & High & Naproxen \\
III & High & Low & Atenolol \\
IV & Low & Low & Furosemide \\
\hline
\end{tabular}

\subsubsection{Drug Analysis by HPLC-UV}

HPLC analysis was performed using the Agilent 1200 HPLC system (Agilent Technologies, Les Ulis, France) with a UV detector (deuterium lamp light source) and with the Uptisphere ${ }^{\circledR}$ C18-ODB $100 \times 2.1 \mathrm{~mm}, 5 \mu \mathrm{m}$ column (Agilent Technologies, Les Ulis, France). Sample preparation was explained in Appendix A. The analysis run time was $20 \mathrm{~min}$. The mobile phase consisted of phase A (phosphate buffer $\mathrm{pH} 7.4$ ) and phase B (acetonitrile). In initial conditions, the mobile-phase composition was 15\% B; a linear gradient was applied to reach a composition of $80 \% \mathrm{~B}$ after $16 \mathrm{~min}$, maintained $2 \mathrm{~min}$, and then set to return to initial. The flow rate was $0.4 \mathrm{~mL} / \mathrm{min}$. Each drug was analyzed separately, and their retention times were: $1.7 \mathrm{~min}$ for atenolol, $4.6 \mathrm{~min}$ for metoprolol, $7.4 \mathrm{~min}$ for propranolol, $6.2 \mathrm{~min}$ naproxen, and $5.6 \mathrm{~min}$ for furosemide. Quantification was achieved using calibration curves (area ratio with internal standard vs. nominal analyte concentration) fitted by linear least squares regression. The lower limit of quantification (LLOQ) was validated at $50 \mathrm{ng} / \mathrm{mL}$ for all substances, and the limit of detection (LOD) was $10 \mathrm{ng} / \mathrm{mL}$.

\subsubsection{Apparent Permeability Calculation}

The apical-to-basolateral apparent permeability was calculated following the equation:

$$
\mathrm{P}_{\mathrm{app}}=\frac{\mathrm{dQ}}{\mathrm{dt}} \times \frac{1}{\mathrm{AC}_{0}}
$$

where $\mathrm{dQ} / \mathrm{dt}$ is the appearance rate of a drug at the basolateral side $(\mu \mathrm{g} / \mathrm{s}), A$ is the surface area of the Transwell ${ }^{\circledR}$ filter $\left(1.12 \mathrm{~cm}^{2}\right)$, and $C_{0}$ is the initial concentration at the apical side $(\mu \mathrm{g} / \mathrm{mL})[21,37]$.

\subsection{Formulation of FRET-LNCS}

\subsubsection{Synthesis of DiI- and DiD-TPB}

The fluorescence dyes DiI- and DiD-tetraphenylborate (TPB) were synthesized by the method previously described $[4,5,10,21]$. Dyes were solubilized in Captex ${ }^{\circledR} 8000$ at the concentration of $2 \% w / w$. 


\subsubsection{Formulation of FRET Lipid Nanocapsules (FRET-LNCs)}

Six formulations of FRET-LNCs were prepared based on the phase inversion method [6]. The surface modification was adapted from the 'one-step (OS) stealth LNCs process' developed by Lainé et al. [38]. The composition of lipid nanocapsules in each batch is described in Table 2. Firstly, Lipoid ${ }^{\circledR}$ S75-3 was dissolved in the Captex ${ }^{\circledR} 8000$ containing DiI-TPB and DiD-TPB. Then, Kolliphor ${ }^{\circledR}$ HS-15, purified water, and $\mathrm{NaCl}$ were added, as well as the surface modification substances, which were DSPE-mPEG (2000) (anionic) or stearylamine (cationic), if applicable. Under agitation, three heat-cool cycles $\left(60-90^{\circ} \mathrm{C}\right)$ were applied to the mixture. In the last cooling cycle, cold ultrapure water $\left(2{ }^{\circ} \mathrm{C}\right)$ was added at the phase inversion temperature, followed by 5 min of a slow stir. Finally, the suspension of FRET-LNCs was filtrated by a $0.22 \mu \mathrm{m}$ filter $\left(\right.$ Minisart $^{\circledR}$ ) and stored at $2-8{ }^{\circ} \mathrm{C}$.

Table 2. Composition of different types of FRET-LNCs.

\begin{tabular}{|c|c|c|c|c|c|c|}
\hline \multirow{2}{*}{ Compositions } & \multicolumn{6}{|c|}{ Quantity $(\% w / w)$} \\
\hline & F1 & F1-DSPE-PEG & F1-SA & F2 & F2-DSPE-PEG & F2-SA \\
\hline Captex ${ }^{\circledR} 8000(2 \% w / w$ DiI-TPB $)$ & 5.5 & 5.5 & 5.5 & 8.5 & 8.5 & 8.5 \\
\hline Captex ${ }^{\circledR} 8000(2 \% w / w$ DiD-TPB $)$ & 5.5 & 5.5 & 5.5 & 8.5 & 8.5 & 8.5 \\
\hline Kolliphor ${ }^{\circledR}$ HS-15 & 11.5 & 11.5 & 11.5 & 9.3 & 9.3 & 9.3 \\
\hline Purified water & 21.3 & 21.3 & 21.3 & 17.5 & 17.5 & 17.5 \\
\hline DSPE-mPEG (2000) & - & 0.6 & - & - & 0.6 & - \\
\hline Stearylamine & - & - & 0.1 & - & - & 0.1 \\
\hline Lipoid $^{\circledR}$ S75-3 & 0.7 & 0.7 & 0.7 & 0.7 & 0.7 & 0.7 \\
\hline $\mathrm{NaCl}$ & 0.8 & 0.8 & 0.8 & 0.8 & 0.8 & 0.8 \\
\hline Purified water $\left(2^{\circ} \mathrm{C}\right)$ & 54.7 & 54.7 & 54.7 & 54.7 & 54.7 & 54.7 \\
\hline
\end{tabular}

\subsection{Characterization of FRET-LNCS}

The concentration (particles $/ \mathrm{mL}$ ) and the size distribution of the nanoparticles were determined with the nanoparticle tracking analysis (NTA) technique using a NanoSight NS300 (Malvern Instrument, Worcestershire, UK) with a low volume flow cell and a $450 \mathrm{~nm}$ laser. FRET-LNCs suspensions were diluted in ultrapure water by factor 300,000 $(v / v)$ and then slowly injected into the sample chamber using a $1 \mathrm{~mL}$ syringe pump with the rate of 3-4 $\mu \mathrm{L}$ per second. The video sequences of the nanoparticles were captured over $60 \mathrm{~s}$ (5 replicates) and then analyzed by NTA analytical software version 3.2.

NTA provides the particle size distribution parameters as D10, D50, and D90; which represents the diameter $(\mathrm{nm})$ at the 10th, 50th (median), and 90th percentiles of the distribution histogram, respectively. Then the span, as a distribution width parameter, is calculated following the equation:

$$
\text { Span }=\frac{\mathrm{D} 90-\mathrm{D} 10}{\mathrm{D} 50}
$$

The zeta potential of the FRET-LNCs was determined by laser doppler electrophoresis using Zetasizer ${ }^{\circledR}$ Nano series DTS 1060 (Malvern Instruments SA, Worcestershire, UK).

\subsection{Transport Assay of Intact LNCs across Membranes \\ 2.8.1. Transport Assay of FRET-LNCs}

First, $1.5 \mathrm{~mL}$ of HBSS and $0.5 \mathrm{~mL}$ of diluted FRET-LNCs (1\% $v / v$ in HBSS) were filled into the basolateral and the apical side of the Transwell ${ }^{\circledR}$ plates, respectively. The plates were incubated for $2 \mathrm{~h}$ at $37^{\circ} \mathrm{C}$ with humidified air and $5 \% \mathrm{CO}_{2}$. Then, samples from the basolateral and the apical sides were collected, and fluorescence was analyzed by spectrophotometer. The TEER of all membranes were measured before and after the experiment to ensure their integrity. Membranes with TEER $<300 \Omega \cdot \mathrm{cm}^{2}$ were excluded from the test. 


\subsubsection{Quantitative FRET Fluorimetry of Intact LNCs}

Fluorescence emission spectra of collected samples were recorded on a FluoroMax ${ }^{\circledR}$ 4 spectrophotometer (Horiba Jobin Yvon Inc., Piscataway, NJ, USA) at room temperature with the $548 \mathrm{~nm}$ excitation and $0.5 \mathrm{~s}$ integration time. The emission spectra were collected from 555 to $750 \mathrm{~nm}$, with an increment of $1 \mathrm{~nm}$. They were corrected for the lamp source fluctuations and the wavelength-dependent response of the detector. The integrity of nanoparticles was determined by FRET efficiency (proximity ratio) calculated by the following equation:

$$
\mathrm{PR}=\frac{\mathrm{A}}{\mathrm{A}+\mathrm{D}}
$$

where $\mathrm{A}$ and $\mathrm{D}$ are the maximum fluorescence intensity of the acceptor $(678 \mathrm{~nm})$ and donor $(569 \mathrm{~nm})$, respectively. The particle concentration of the nanocarriers was calculated from the standard curve of the FRET acceptor signal. An acceptor signal lower than the limit of detection $(\mathrm{LOD}=1382 \mathrm{cps} / \mathrm{mA}$ ) and/or a PR lower than 0.70 was considered as zero particle concentration.

\subsubsection{Transport Efficiency of FRET-LNCs}

The transport efficiency (TE) of FRET-LNCs is the percentage of numbers of nanoparticles presenting at the basolateral medium compared to the initial particle concentration at the apical medium. It was calculated by the equation:

$$
\mathrm{TE}=\frac{\mathrm{C}_{\mathrm{f}} \mathrm{V}_{\mathrm{B}}}{\mathrm{C}_{0} \mathrm{~V}_{\mathrm{A}}} \times 100 \%
$$

where $C_{f}$ is the particle concentration at the basolateral side after $2 \mathrm{~h}, \mathrm{C}_{0}$ is the initial particle concentration at the apical side (particles $/ \mathrm{mL}$ ), $\mathrm{V}_{\mathrm{A}}$ is the volume of sample at the apical side $(1 \mathrm{~mL})$, and $\mathrm{V}_{\mathrm{B}}$ is the volume of sample at the basolateral side $(1.5 \mathrm{~mL})$.

\subsection{Statistical Analysis}

The experiments were performed at least in triplicate. For statistical comparison, the Kruskal-Wallis test with uncorrected Dunn's multiple comparison test was the method of statistical analysis. $p$-value of less than or equal to 0.05 was considered statistically significant. All statistical analysis was performed using Prism GraphPad (version 8.4.1, GraphPad Software, San Diego, CA, USA).

\section{Results and Discussions}

\subsection{Development of the New In Vitro Coculture Model}

The new in vitro 2D coculture model between Caco-2 and HMEC-1 cells was developed and intended as a tool to assess the absorption of drugs and nanoparticles. In order to investigate its morphology, cross-sections of cell layers were observed under TEM (Figure 1A). On day 22, Caco-2 cells exhibited a columnar epithelium monolayer structure with $\sim 25 \mu \mathrm{m}$ thickness with a brush border (microvilli) on the apical surface. When zooming in between the adjacent borders of two Caco-2 cells, junctional complex structures were observed. The morphology of these Caco-2 cells corresponds to mature human enterocytes $[23,39,40]$ and typical Caco-2 cells described elsewhere [41,42]. Furthermore, the HMEC-1 layer was obtained as a very thin squamous epithelium monolayer with $0.2-2 \mu \mathrm{m}$ thickness covering the basolateral side of the filter (facing downward). The junctional structure was observed along HMEC-1 cell borders. This morphology of HMEC-1 is closely similar to the structure of human vascular endothelium already described by Young et al. and Ru et al. [40,42]. Thus, with this coculture condition, the morphology of both Caco-2 and HMEC-1 cells was maintained. 
(A)
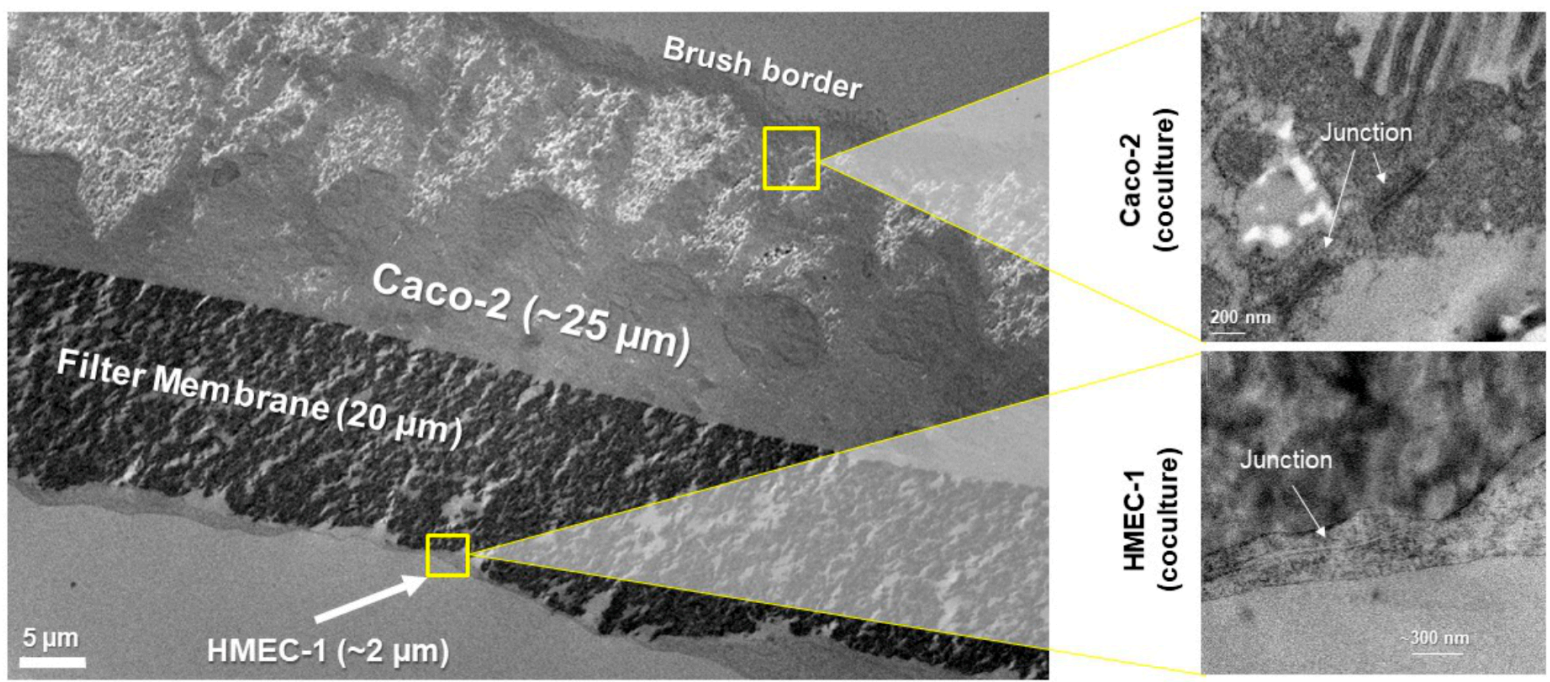

(B)

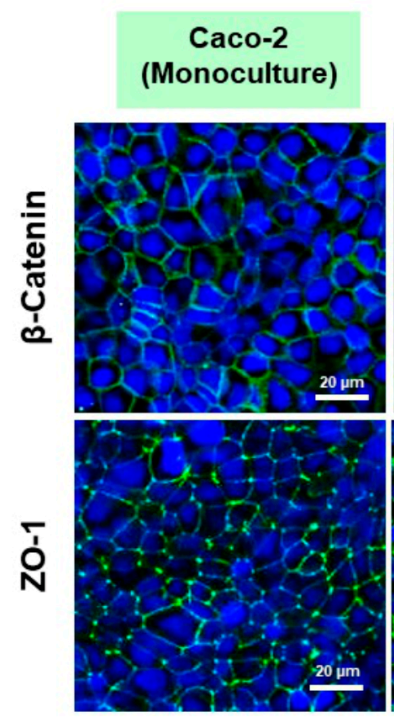

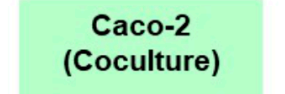
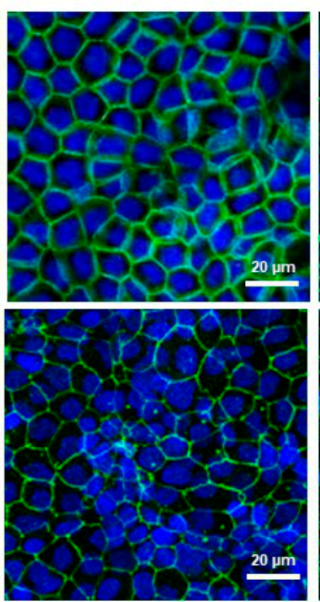
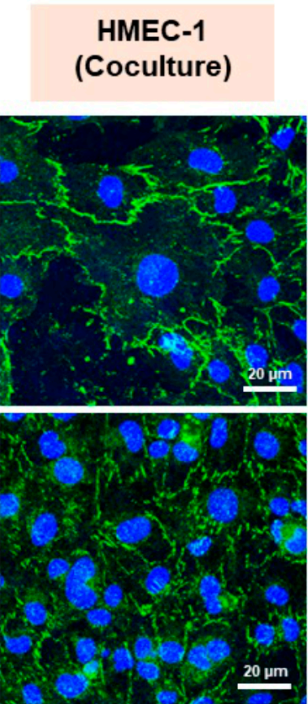

(C)

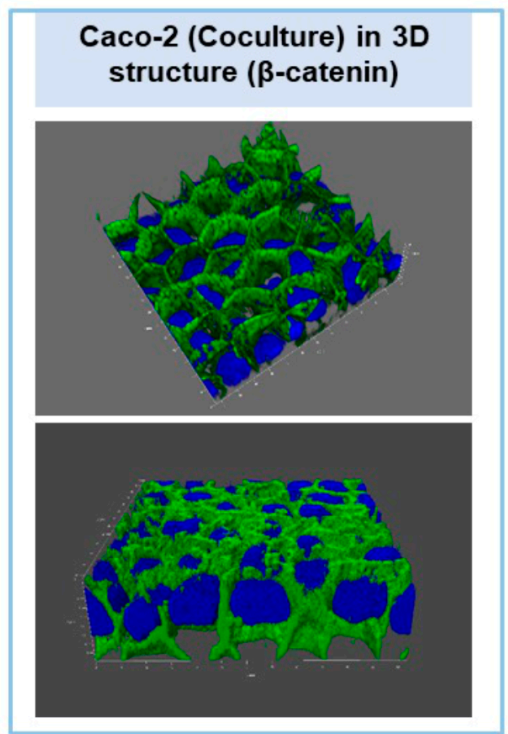

Figure 1. (A) Cross-sectioning images of Caco-2 and HMEC-1 coculture layers under TEM (left) and zoomed cross-sectioning images of the junction area between Caco-2 cells (upper right) and HMEC-1 cells (lower right); (B) immunofluorescent staining images of Caco-2 monoculture, cocultured Caco-2 and cocultured HMEC-1 layers, characterized by confocal microscopy for the expression of tight junction protein ZO-1 (Alexa Fluor ${ }^{\circledR} 488$, green) and adherens junction protein $\beta$-catenin (Alexa Fluor ${ }^{\circledR} 488$, green). The images are overlayed with cell nuclei (DAPI, blue); (C) the 3D images show only the expression of $\beta$-catenin in the cocultured Caco-2 layer and revealed a confluent monolayer with no cell stacking.

In order to investigate the formation of the cell junctional complex, the expression of tight junction protein $\mathrm{ZO}-1$ and adherens junction protein $\beta$-catenin were examined by immunofluorescence (Figure 1B). HMEC-1 and Caco-2 cell layers in the coculture model were confluent with the expression of $\mathrm{ZO}-1$ and $\beta$-catenin along the cell borders, meaning that tight junctions and adherens junctions were fully developed. A similar structural pattern was observed (Figure 1B) in the Caco-2 monolayer, meaning that the coculture system still maintained the same junctional complex structure as in monoculture. In accordance with our study, Ma et al. described that Caco-2 expressed the ZO-1 as a continuous band along the cell borders after 3 weeks of incubation, while Rüffer et al. 
found that HMEC-1 expressed ZO-1 and also $\beta$-catenin at the cell borders after 3 days of incubation [39]. In addition, a 3D imagery of $\beta$-catenin overlayed with cell nuclei (Figure 1C) revealed that the cocultured Caco-2 had a structure of a confluent monolayer with no cell stacking. As such, a confluent monolayer of Caco-2 and HMEC-1 cocultured on the apical and basolateral side of the Transwell ${ }^{\circledR}$ filter, respectively, was obtained.

The membrane integrity of cell culture membranes was also monitored by TEER measurement from the beginning to the end of the cell culture. As shown in Figure 2, the average TEER of the Caco-2/HMEC-1 coculture model on day 22 had the highest level, with an average of $1415 \pm 331 \Omega \cdot \mathrm{cm}^{2}$. This average is significantly (Kruskal-Wallis) higher than that of the Caco-2 model $\left(470 \pm 46 \Omega \cdot \mathrm{cm}^{2}\right)$, which was also significantly (KruskalWallis) higher than HMEC-1 monolayer $\left(18 \pm 6 \Omega \cdot \mathrm{cm}^{2}\right)$. Besides, the TEER of the Caco-2 model was in accordance with Briske-Anderson et al., who cultured the Caco-2 cells from passage 22 with similar conditions and obtained a TEER value at around $500 \Omega \cdot \mathrm{cm}^{2}$ after 21 days [43-49].

\section{TEER of cell culture models}

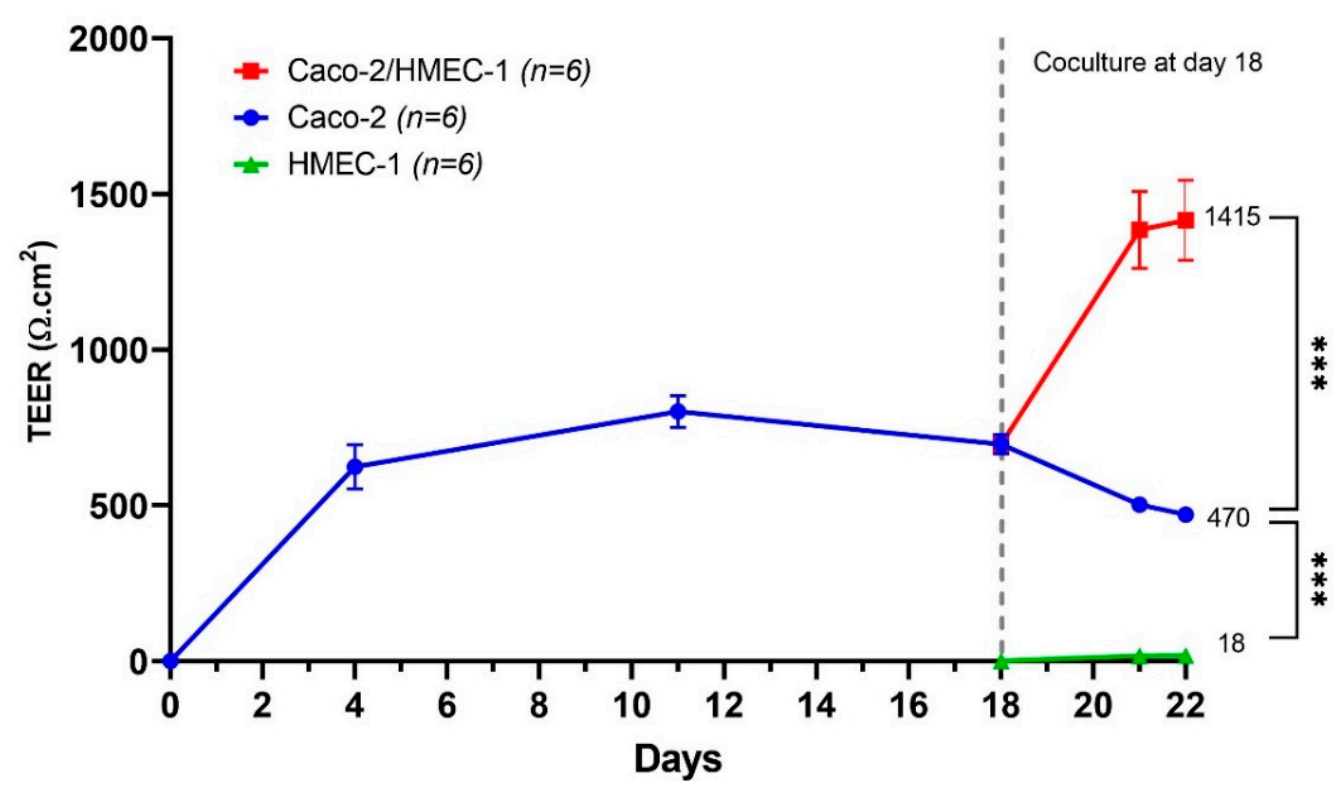

Figure 2. Average TEER $(n=6)$ of Caco-2/HMEC-1 coculture (red), Caco-2 monolayer (blue), and HMEC-1 monolayer (green). The whiskers represent a 95\% confidence interval (Kruskal-Wallis: ${ }^{* * *} p \leq 0.001$ ).

Since this new in vitro coculture model was intended as a tool to assess drug absorption, the apical-to-basolateral $\mathrm{P}_{\mathrm{app}}$ of five reference drugs from all four BCS classes was evaluated and compared with their $\mathrm{P}_{\text {app }}$ from the conventional Caco-2 model (Figure 3). The five drugs in this experiment are chosen because they are commonly used as the reference for evaluating the permeability in the Caco-2 model. Their solubility and permeability are defined by the BCS [45-51]. For atenolol (class III) and furosemide (class IV), the concentration at the basolateral side was lower than the detection limit in both coculture and Caco-2 models. These results were in accordance with the definition of classes III and IV, which have low apparent permeability. For propranolol (class I), metoprolol (class I), and naproxen (class II), their $\mathrm{P}_{\text {app }}$ were ranging from 20.6 to $44.2 \times 10^{-6} \mathrm{~cm} / \mathrm{s}$ on the coculture model and 22.4 to $44.5 \times 10^{-6} \mathrm{~cm} / \mathrm{s}$ on the Caco-2 model, conforming with the BCS classification as well. No significant differences (Kruskal-Wallis) between the $\mathrm{P}_{\text {app }}$ of all five drugs across the coculture and the Caco-2 model were obtained. Therefore, the $\mathrm{P}_{\text {app }}$ of both Caco-2/HMEC-1 and Caco-2 models were in the same range for the five tested drugs. These values were also similar to those from various literature that high-permeability drugs in BCS class I and II had the $P_{\text {app }}$ in the range from $9 \times 10^{-6}$ to $43 \times 10^{-6} \mathrm{~cm} / \mathrm{s}$, while low- 
permeability drugs in class III and IV had nearly zero $P_{\text {app }}[6,7,10-17]$. In addition, the $P_{\text {app }}$ of the drugs across the HMEC-1 monolayer and the blank Transwell ${ }^{\circledR}$ filter (Figure S1) was also examined as a control. The $\mathrm{P}_{\text {app }}$ of all drugs were in the same range from $22 \times 10^{-6}$ to $34 \times 10^{-6} \mathrm{~cm} / \mathrm{s}$ with no significant difference (Kruskal-Wallis) between drugs of high and low permeability across both HMEC-1 monolayer and blank filter. In conclusion, the addition of the HMEC-1 layer in the coculture model did not change the permeability of these five references drugs across the membranes, suggesting that the conventional Caco-2 model alone might be adequate for studying the absorption of drug molecules.

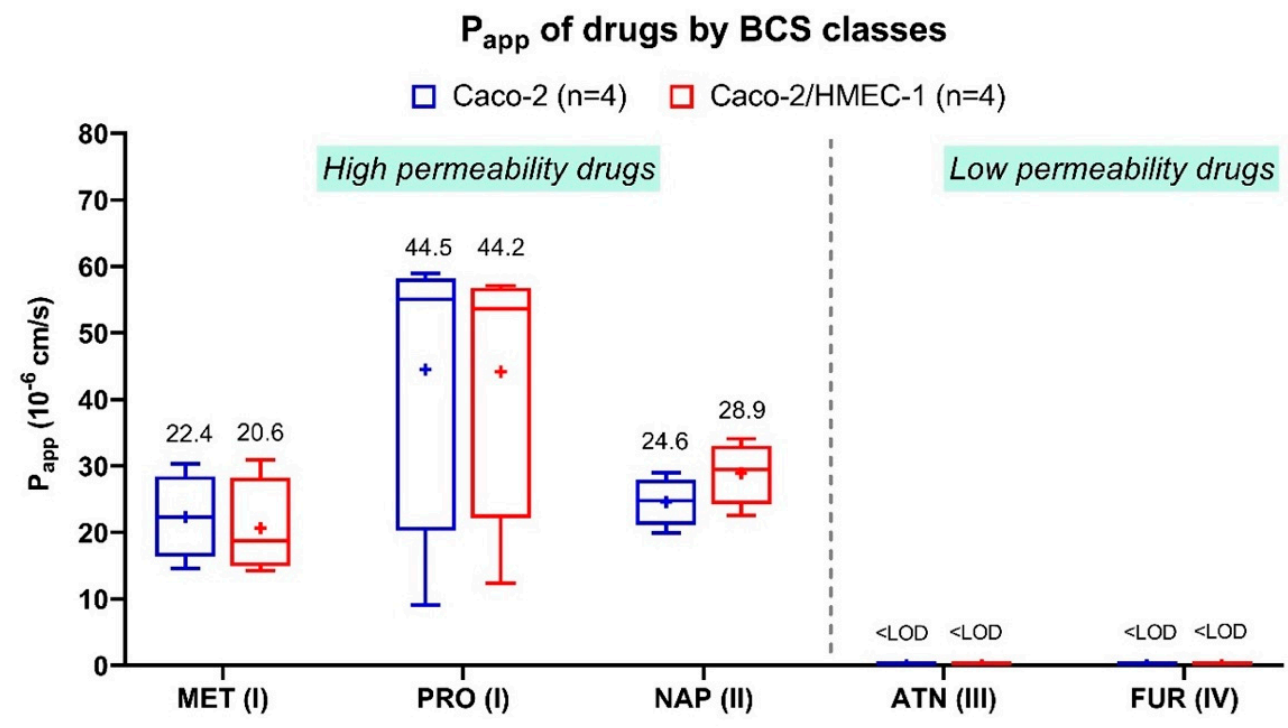

Figure 3. Average apparent permeability $\left(\mathrm{P}_{\mathrm{app}}\right)$ of five drugs $(n=4)$ classified by four BCS classes across Caco-2 cells (blue) and HMEC-1/Caco-2 coculture cells (red). MET = metoprolol, $\mathrm{PRO}=$ propranolol, $\mathrm{NAP}=$ naproxen, $\mathrm{ATN}=$ atenolol, $\mathrm{FUR}=$ furosemide; BCS class numbers are signified in the parentheses. LOD means the limit of detection $=10 \mathrm{ng} / \mathrm{mL}$. The $(+)$ symbol represents the arithmetic mean, and the whiskers represent a 95\% confidence interval (Kruskal-Wallis).

\subsection{Transport Assay of Intact LNCs across Membranes}

LNCs demonstrated their ability to improve the oral absorption of several encapsulated drugs [50]. Nanoparticle size can also influence oral drug absorption [7,51]. Furthermore, surface-modified LNCs such as PEG (2000)-amino post-inserted LNCs and stearylamine LNCs can enhance oral drug bioavailability [21]. Hence, in order to study the impact of size and surface chemistry of LNCs on their oral in vitro absorption, the LNCs with two different sizes (F1 and F2) and three different surface chemistry (unmodified LNCs, anionic DSPE-mPEG (2000) added, and cationic stearylamine added) were formulated (Table 2) and tested in both coculture and Caco-2 models. In addition, Roger et al. have recently shown that the FRET technique could be used to detect and quantify the intact LNCs crossing the Caco-2 monolayer [4,5]. Thus, in order to monitor the integrity of LNCs across the membrane, the FRET technique was used.

Table 3 presents the physicochemical characteristics of the FRET-LNCs in terms of hydrodynamic size, particle size distribution, particle concentration, zeta potential, and FRET proximity ratio. The size distribution histogram is shown in Figure S2. The composition F1 and F2 provided the FRET-LNCs with an average diameter of around $55 \mathrm{~nm}$ and $85 \mathrm{~nm}$, respectively. The F2 formulation group has a higher amount of Captex ${ }^{\circledR} 8000$ (oily core) and a slightly lower amount of Kolliphor ${ }^{\circledR}$ HS-15 than the F1 group. In accordance with the ternary diagram of a mixture system established by Heurtault et al. [6,10] and other previous studies [5], increasing the amount of oil composition together with decreasing the amount of the hydrophilic surfactant (Kolliphor ${ }^{\circledR}$ HS-15) could increase the size of LNCs [21]. Moreover, the particle size distribution of all formulations was unimodal and uniform (Figure S2). The D50 value is the median diameter (nm). All the formulations had 
a symmetric distribution as their median diameter was almost equal to the mean diameter. Besides, span is the parameter determining the size distribution width normalized by median diameter. The span value closing to zero determines a narrow size distribution. The span of the compositions F1 (0.37-0.38) was lower than the F2 (0.54-0.63), indicating that LNCs with smaller sizes had a narrower distribution width, while the surface modification had no effect on altering the distribution width (Kruskal-Wallis). Furthermore, both F1 and F2 compositions had similar particle concentrations (Kruskal-Wallis) ranging from $5.5 \times 10^{14}$ to $8.0 \times 10^{14}$ particles $/ \mathrm{mL}$ and slightly lower than previously reported in the literature at $1.2 \times 10^{15}$ particles/mL for $55 \mathrm{~nm}$ LNCs [20]. By contrast, the zeta potential of F2 was higher than F1 (16.3 $\pm 3.7 \mathrm{mV}$ and $4.1 \pm 0.8$, respectively), but such a difference was not observed in the blank F1 and F2 formulations (containing no FRET dyes), of which the zeta potential was around $-5.0 \mathrm{mV}$ regardless of sizes. The FRET dyes DiI-TPB and DiD-TPB used in the formulation were positively charged and were previously reported to elevate the zeta potential of 55-nm LNCs [6]. The fact that F2 had a quantity of Captex ${ }^{\circledR}$ 8000, in which FRET dyes were dissolved, higher than F1 could explain the higher zeta potential in F2.

Table 3. Characterization of FRET-LNCs (mean \pm SD): particle size, particle size distribution, particle concentration, zeta potential, and proximity ratio.

\begin{tabular}{|c|c|c|c|c|c|c|c|c|}
\hline \multirow{2}{*}{ Formulas } & \multirow{2}{*}{$\begin{array}{l}\text { Particle Size } \\
\quad(\mathrm{nm})\end{array}$} & \multicolumn{4}{|c|}{ Particle Size Distribution } & \multirow{2}{*}{$\begin{array}{c}\text { Particle Concentration }\left(\times 10^{14}\right. \\
\text { Particles } / \mathrm{mL})\end{array}$} & \multirow{2}{*}{$\begin{array}{l}\text { Zeta Potential } \\
(\mathrm{mV})\end{array}$} & \multirow{2}{*}{$\begin{array}{c}\text { FRET Proximity } \\
\text { Ratio }\end{array}$} \\
\hline & & D10 (nm) & D50 (nm) & D90 (nm) & Span & & & \\
\hline $\begin{array}{c}\text { F1 }(n=3) \\
\text { F1-DSPE-PEG }(n=2)\end{array}$ & $\begin{array}{c}57.8 \pm 9.7 \\
53.1\end{array}$ & $\begin{array}{l}45.3 \pm 5.0 \\
42.7\end{array}$ & $\begin{array}{c}54.2 \pm 7.7 \\
50.9\end{array}$ & $\begin{array}{c}65.6 \pm 12.5 \\
62.5\end{array}$ & $\begin{array}{c}0.37 \pm 0.08 \\
0.38\end{array}$ & $7.7 \pm 1.2$ & $4.1 \pm 0.8$ & $0.89 \pm 0.04$ \\
\hline F1-SA $(n=3)$ & $56.0 \pm 5.6$ & $45.3 \pm 4.5$ & $53.5 \pm 5.1$ & $65.6 \pm 7.2$ & $\begin{array}{c}0.38 \\
0.38 \pm 0.04\end{array}$ & $8.0 \pm 3.1$ & $\begin{array}{l}-4.9 \\
15.4 \pm 2.1\end{array}$ & $\begin{array}{c}0.89 \\
0.89 \pm 0.04\end{array}$ \\
\hline $\mathrm{F} 2(n=3)$ & $92.6 \pm 10.0$ & $67.1 \pm 6.2$ & $88.5 \pm 8.9$ & $120.4 \pm 15.3$ & $0.60 \pm 0.04$ & $5.5 \pm 2.7$ & $16.3 \pm 3.7$ & $0.93 \pm 0.02$ \\
\hline F2-DSPE-PEG $(n=2)$ & 83.3 & 61.3 & 77.3 & 109.9 & 0.63 & 6.6 & 3.2 & 0.92 \\
\hline F2-SA $(n=3)$ & $82.6 \pm 5.8$ & $62.3 \pm 3.7$ & $78.7 \pm 5.2$ & $104.7 \pm 9.9$ & $0.54 \pm 0.07$ & $6.8 \pm 2.3$ & $27.3 \pm 2.8$ & $0.93 \pm 0.02$ \\
\hline
\end{tabular}

Adding anionic DSPE-mPEG (2000) and cationic stearylamine at the formulation of FRET-LNCs did not significantly change the size and the particle concentration (KruskalWallis, see Table 3). However, adding DSPE-mPEG (2000) decreased the zeta potential by 9-13 mV, whilst stearylamine increased it by $11 \mathrm{mV}$, as already described by Lainé et al. [7] and Ramadan et al. [52,53].

Finally, to determine the integrity of LNCs, the FRET proximity ratio (PR) was calculated [21]. Intact LNCs have PR closer to 1 due to the highly efficient energy transfer between FRET dyes in close proximity, while broken LNCs can have PR as low as 0.22 or less [54]. The PR of all formulations (Table 3) ranged from 0.89 to 0.93 , meaning that the FRET dyes DiI-TPB/DiD-TPB were well encapsulated, and the formulations were full of intact LNCs. Size or surface modifications had no significant effect on PR. In summary, six FRET-LNCs formulations with different sizes and surface modifications were successfully developed and suitable for the transport assay experiment.

The transport of the six formulations was investigated in the Caco-2 and the Caco2/HMEC-1 coculture model. The transport efficiency (TE) of each formulation is shown in Figure 4. In the Caco-2 model, when compared by sizes and surface-chemistry, the TEs of all different LNCs did not show statistically significant differences (Kruskal-Wallis). In the coculture model, when compared by sizes, the F2, F2-DSPE-PEG, and F2-SA had higher trends of TEs than their F1 counterparts, but no statistical significance (KruskalWallis) was found. Furthermore, when compared by surface-chemistry, only F1-DSPE-PEG could increase the TEs of F1 with a statistical significance (Kruskal-Wallis). Finally, when compared between models, the TEs of F1-DSPE-PEG, F2-DSPE-PEG, and F2-SA were found to be higher, with a statistical significance (Kruskal-Wallis), in the coculture model than in the Caco-2 model, while in the coculture model, the TEs of F1-DSPE-PEG, F2-DSPEPEG, and F2-SA were lower than the detection limit (reported as TE $=0$ ). Summarily, results clearly showed a different pattern of TEs between the two models, meaning that the addition of an endothelium layer to the Caco-2 one increases the TE of F1-DSPE-PEG, F2-DSPE-PEG, and F2-SA. LNCs size did not affect TE in both models, while the surface chemistry had an effect on TE but only with F1-DSPE-PEG (55-nm). 


\section{Transport Efficiency of FRET-LNCs after $2 \mathrm{~h}$}

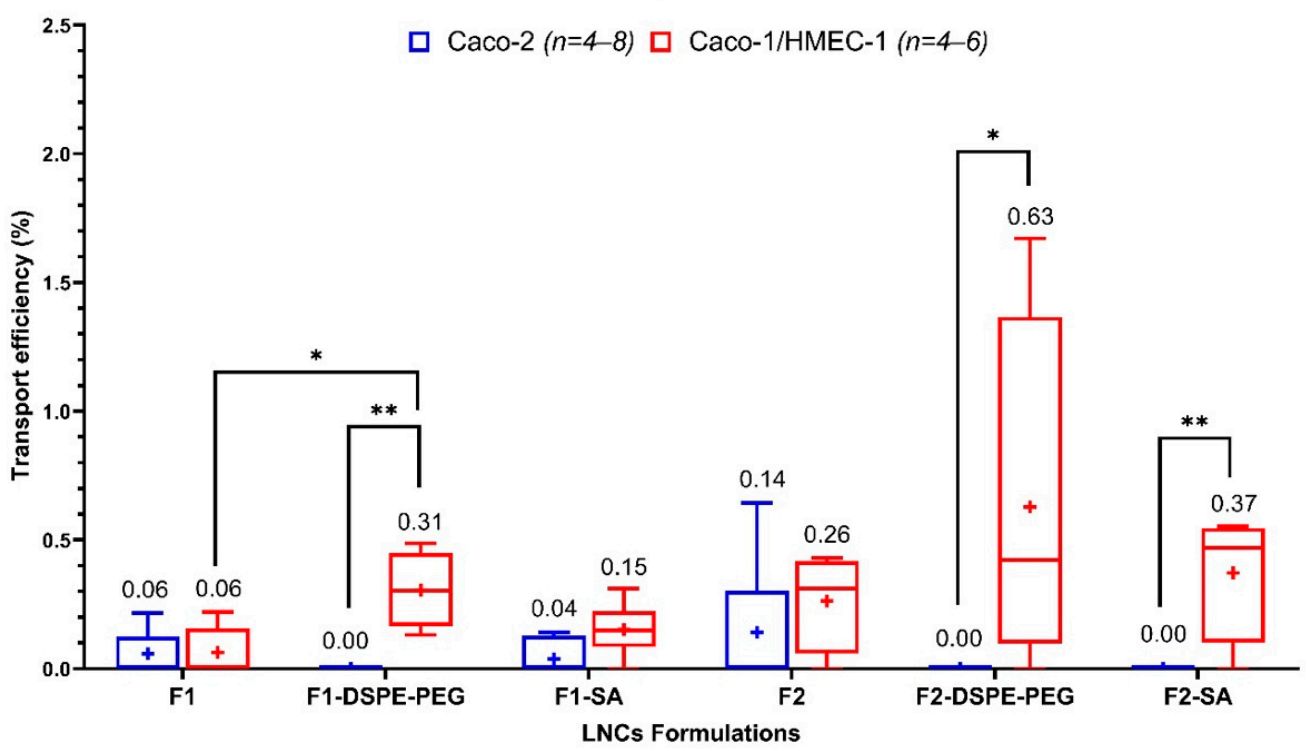

Figure 4. Transport efficiency of six FRET-LNCs formulations after $2 \mathrm{~h}$ in the Caco-2 model (blue, $n=4-8$ ), and the Caco-2/HMEC-1 coculture model (red, $n=4-6)$. The $(+)$ symbols represent the arithmetic mean, and the whiskers represent a $95 \%$ confidence interval (Kruskal-Wallis: ${ }^{*} p \leq 0.05,{ }^{* *} p \leq 0.01$ ).

Using the new coculture model revealed that F1-DSPE-PEG had a significantly higher transport efficiency than F1, meaning that adding DSPE-mPEG (2000) to the surface of 55$\mathrm{nm}$ LNCs increased their in vitro intestinal absorption. A similar result has been observed by Bannunah et al. [54], who described that anionic polystyrene nanoparticles (PS-NPs) had much higher transportation across the Caco-2 model than cationic PS-NPs. More precisely, transcytosis of anionic PS-NPs mainly occurred via the caveolae-mediated pathway, while it was not the case for cationic PS-NPs whose transcytosis occurred via the clathrin-mediated pathway [55,56]. Moreover, adding more PEG chains, like DSPE-mPEG (2000), to the surface of LNCs would also improve their mucopenetrating property [43-48].

Interestingly, the different absorption patterns between the two models only appeared among the LNCs but not among the reference molecular drugs (Figure 3). Some LNCs, but none of the reference drugs, had significantly higher absorption in the coculture model despite its higher membrane integrity (TEER). Molecular drugs are mainly absorbed via the passive pathway regulated by the membrane's chemical properties rather than the biological ones [10,57-59]. By contrast, the LNCs are absorbed by active transport via the caveolae-mediated or clathrin/caveolae-independent endocytosis in the Caco-2 model [5759]. The hydrophilic surfactant (Kolliphor ${ }^{\circledR}$ HS-15, previously named Solutol ${ }^{\circledR}$ HS-15) on the outer shell of LNCs could directly interact with the cholesterol-rich microdomain (lipid raft) on the cell surface, inciting the endocytosis [57-59]. The difference in LNCs absorption between the Caco- 2 and the coculture models implied that adding the HMEC-1 layer might cause a change in the cell's biological absorption process that affected the LNCs transcytosis, but not the membrane's chemical properties that affected molecular drugs absorption. Therefore, the next step of this work is to determine the LNCs transport mechanism across this coculture model.

\section{Conclusions}

In conclusion, a new coculture model of Caco-2 intestinal epithelium and human primary vascular endothelium cells (HMEC-1) was successfully developed. The cell morphology, membrane integrity, and drug permeability were validated and proved that the new model was suitable for a tool to evaluate the absorption of drugs and nanoparticles. Improving the conventional Caco- 2 model by adding the endothelium layer could change the absorption pattern of LNCs but not drugs in solution. This suggests the necessity of the 
new coculture model for studying the absorption of LNCs or other nanocarrier systems. However, for studying the absorption of drug in solutions, the Caco- 2 model should be adequate. By using the coculture model, the absorption of DSPE-mPEG (2000) LNCs (55- nm and 85-nm) and stearylamine LNCs (85-nm) was found to be surprisingly higher, despite the coculture model's higher TEER. Furthermore, the new model also revealed the increase in the absorption of 55-nm LNCs when surfaced-modified by DSPE-mPEG (2000). All these distinct absorption patterns between the two models imply the differences in the LNCs transport mechanism and are the proof of concept for the effect and the importance of the intestinal endothelium on the transportation of nanoparticles across gut barriers. The use of the new coculture model combined with the FRET technique could provide a better understanding of the fate of intact LNCs across the intestinal barriers. For future experiments, the details on the transport mechanism of LNCs in the coculture model should be elucidated. The in vivo-in vitro correlation (IVIVC) of intact LNCs should be further investigated. Besides, the new model should also be used to study the absorption of other types of nanocarriers.

Supplementary Materials: The following are available online at https://www.mdpi.com/article/ 10.3390/pharmaceutics13050595/s1, Figure S1: Average apparent permeability $\left(\mathrm{P}_{\text {app }}\right)$ of five drugs $(n=4)$ classified by four BCS classes across HMEC-1 monolayer (green) and blank Transwell ${ }^{\circledR}$ filter (gray). $\mathrm{MET}=$ metoprolol, $\mathrm{PRO}$ = propranolol, $\mathrm{NAP}=$ naproxen, $\mathrm{ATN}$ = atenolol, $\mathrm{FUR}=$ furosemide; BCS class numbers are signified in the parentheses. The (+) symbol represents the arithmetic mean, and the whiskers represent a 95\% confidence interval (Kruskal-Wallis). Figure S2: Example of the particle size distribution histogram of the formulations (A-F): F1, F1-DSPE-PEG, F1-SA, F2, F2-DSPE-PEG, and F2-SA, respectively.

Author Contributions: Methodology, N.K., E.R., S.L., and C.A.; validation, N.K., E.R., and S.L.; formal analysis, N.K.; investigation, N.K., J.B., N.L., F.M., R.P., C.A., and M.B.; resources, J.B. and N.L.; data curation, N.K.; writing — original draft preparation, N.K.; writing—review and editing, N.K., E.R. and S.L.; visualization, N.K., F.M., and R.P.; supervision, E.R. and S.L.; project administration, E.R. and S.L.; funding acquisition, E.R. and S.L. All authors have read and agreed to the published version of the manuscript.

Funding: This work was supported by the Ligue Contre le Cancer, Maine-et-Loire and CharenteMaritime Committees (JPB/FP—223/12.2020), France; and the University of Angers, France.

Institutional Review Board Statement: Not applicable.

Informed Consent Statement: Not applicable.

Data Availability Statement: All data generated or analyzed during this study are included in this published article and its Supplementary information files.

Conflicts of Interest: The authors declare no conflict of interest. The funders had no role in the design of the study; in the collection, analyses, or interpretation of data; in the writing of the manuscript, or in the decision to publish the results.

\section{Appendix A. Sample Preparation for Drug Assay by HPLC-UV}

Appendix A.1. Sample Preparation for Metoprolol and Propranolol

The internal standard was prepared as a solution of $20 \mathrm{mg} / \mathrm{L}$ protriptyline (in methanol) for propranolol and $20 \mathrm{mg} / \mathrm{L}$ methyl milnacipran (in methanol) for metoprolol. Then, $25 \mu \mathrm{L}$ of the internal standard and $100 \mu \mathrm{L}$ of $4 \mathrm{M} \mathrm{NaOH}$ were added to $500 \mu \mathrm{L}$ of the sample. Afterward, liquid-liquid extraction using $4 \mathrm{~mL}$ of hexane/isoamyl alcohol $(80 / 20, v / v)$ was performed, and $100 \mu \mathrm{L}$ of $0.02 \mathrm{M} \mathrm{HCl}$ was added to the organic phase after mixing. The mixture was centrifugated, and the supernatant was eliminated. $10 \mu \mathrm{L}$ of the preparation was injected into the chromatographic system. 


\section{Appendix A.2. Sample Preparation for Naproxen}

The internal standard was prepared as a solution of $50 \mathrm{mg} / \mathrm{L}$ tolbutamide (in acetonitrile). Then, $200 \mu \mathrm{L}$ of the internal standard was added to $50 \mu \mathrm{L}$ of the sample. The preparation was then centrifuged, and $10 \mu \mathrm{L}$ of the supernatant was injected into the chromatographic system.

\section{Appendix A.3. Sample Preparation for Atenolol}

The internal standard was prepared as a solution of $20 \mathrm{mg} / \mathrm{L}$ prazepam (in methanol). Then, $25 \mu \mathrm{L}$ of the internal standard was added to $500 \mu \mathrm{L}$ of the sample. Afterward, liquidliquid extraction using $5 \mathrm{~mL}$ of dichloromethane and $30 \mu \mathrm{L}$ of $1 \mathrm{M} \mathrm{NaOH}$ was performed. After mixing, the mixture was centrifugated, and the supernatant (organic phase) was collected and evaporated to dryness at $50^{\circ} \mathrm{C}$ under nitrogen gas. The residue was dissolved in $50 \mu \mathrm{L}$ of methanol and $20 \mu \mathrm{L}$ of water. $10 \mu \mathrm{L}$ of the preparation was injected into the chromatographic system.

\section{Appendix A.4. Sample Preparation for Furosemide}

The internal standard was prepared as a solution of $50 \mathrm{mg} / \mathrm{L}$ tolbutamide (in acetonitrile). Then, $25 \mu \mathrm{L}$ of the internal standard and $200 \mu \mathrm{L}$ of ammonium acetate buffer $\mathrm{pH} 4.0$ were added to $200 \mu \mathrm{L}$ of the sample. Afterward, liquid-liquid extraction using $1.5 \mathrm{~mL}$ of dichloromethane was performed. After mixing, the mixture was centrifugated, and the supernatant (organic phase) was collected and evaporated to dryness at $50{ }^{\circ} \mathrm{C}$ under a nitrogen stream. The residue was dissolved in $50 \mu \mathrm{L}$ of methanol and $20 \mu \mathrm{L}$ of water. $10 \mu \mathrm{L}$ of the preparation was injected into the chromatographic system.

\section{References}

1. König, J.; Wells, J.; Cani, P.D.; García-Ródenas, C.L.; MacDonald, T.; Mercenier, A.; Whyte, J.; Troost, F.; Brummer, R.J. Human Intestinal Barrier Function in Health and Disease. Clin. Trans. Gastroenterol. 2016, 7. [CrossRef] [PubMed]

2. Groschwitz, K.R.; Hogan, S.P. Intestinal Barrier Function: Molecular Regulation and Disease Pathogenesis. J. Allergy Clin. Immunol. 2009, 124, 3-20. [CrossRef]

3. Bischoff, S.C.; Barbara, G.; Buurman, W.; Ockhuizen, T.; Schulzke, J.D.; Serino, M.; Tilg, H.; Watson, A.; Wells, J.M. Intestinal Permeability-A New Target for Disease Prevention and Therapy. BMC Gastroenterol. 2014, 14, 1-25. [CrossRef] [PubMed]

4. Heurtault, B.; Saulnier, P.; Pech, B.; Proust, J.E.; Benoit, J.P. A Novel Phase Inversion-Based Process for the Preparation of Lipid Nanocarriers. Pharm. Res. 2002, 19, 875-880. [CrossRef]

5. Heurtault, B.; Saulnier, P.; Pech, B.; Venier-Julienne, M.C.; Proust, J.E.; Phan-Tan-Luu, R.; Benoît, J.P. The Influence of Lipid Nanocapsule Composition on Their Size Distribution. Eur. J. Pharm. Sci. 2003, 18, 55-61. [CrossRef]

6. Lainé, A.L.; Gravier, J.; Henry, M.; Sancey, L.; Béjaud, J.; Pancani, E.; Wiber, M.; Texier, I.; Coll, J.L.; Benoit, J.P.; et al. Conventional versus Stealth Lipid Nanoparticles: Formulation and in Vivo Fate Prediction through FRET Monitoring. J. Control. Release 2014, 188, 1-8. [CrossRef]

7. Ramadan, A.; Lagarce, F.; Pierre, L.; Tessier-Marteau, A.; Thomas, O.; Macchi, L.; Saulnier, P.; Benoit, J.-P. Oral Fondaparinux: Use of Lipid Nanocapsules as Nanocarriers and in Vivo Pharmacokinetic Study. Int. J. Nanomed. 2011, 6, 2941-2951. [CrossRef]

8. Messaoudi, K.; Saulnier, P.; Boesen, K.; Benoit, J.; Lagarce, F. Anti-Epidermal Growth Factor Receptor SiRNA Carried by Chitosan-Transacylated Lipid Nanocapsules Increases Sensitivity of Glioblastoma Cells to Temozolomide. Int. J. Nanomed. 2014, 9, 1479-1490.

9. Eissa, M.M.; El-Moslemany, R.M.; Ramadan, A.A.; Amer, E.I.; El-Azzouni, M.Z.; El-Khordagui, L.K. Miltefosine Lipid Nanocapsules for Single Dose Oral Treatment of Schistosomiasis Mansoni: A Preclinical Study. PLoS ONE 2015, 10, e0141788. [CrossRef]

10. Roger, E.; Lagarce, F.; Garcion, E.; Benoit, J.P. Lipid Nanocarriers Improve Paclitaxel Transport throughout Human Intestinal Epithelial Cells by Using Vesicle-Mediated Transcytosis. J. Control. Release 2009, 140, 174-181. [CrossRef]

11. Peltier, S.; Oger, J.; Couet, W.; Beno1, J. Enhanced Oral Paclitaxel Bioavailability After Administration of Paclitaxel-Loaded Lipid Nanocapsules. Pharm. Res. 2006, 23, 1243-1250. [CrossRef]

12. Pensel, P.E.; Ullio, G.; Fabbri, J.; Ceballos, L.; Sanchez, S.; Alvarez, L.I.; Allemandi, D.; Pierre, J.; Palma, S.D.; Elissondo, M.C. Acta Tropica Cystic Echinococcosis Therapy: Albendazole-Loaded Lipid Nanocapsules Enhance the Oral Bioavailability and Efficacy in Experimentally Infected Mice. Acta Trop. 2015, 152, 185-194. [CrossRef] [PubMed]

13. Amara, R.O.; Ramadan, A.A.; El-Moslemany, R.M.; Eissa, M.M.; El-Azzouni, M.Z.; El-Khordagui, L.K. Praziquantel-Lipid Nanocapsules: An Oral Nanotherapeutic with Potential Schistosoma Mansoni Tegumental Targeting. Int. J. Nanomed. 2018, 13, 4493-4505. [CrossRef] 
14. Abozaid, D.; Ramadan, A.; Barakat, H.; Khalafallah, N. Acyclovir Lipid Nanocapsules Gel for Oromucosal Delivery: A Preclinical Evidence of Efficacy in the Chicken Pouch Membrane Model. Eur. J. Pharm. Sci. 2018, 121, 228-235. [CrossRef] [PubMed]

15. Briot, T.; Roger, E.; Verger, A.; Clavreul, A.; Lagarce, F. Development and in Vitro Evaluations of New Decitabine Nanocarriers for the Treatment of Acute Myeloid Leukemia. Int. J. Nanomed. 2017, 12, 8427-8442. [CrossRef]

16. Varshosaz, J.; Taymouri, S.; Jahanian-najafabadi, A.; Alizadeh, A. Efavirenz Oral Delivery via Lipid Nanocapsules: Formulation, Optimisation, and Ex-Vivo Gut Permeation Study. IET Nanobiotechnol. 2018, 12, 795-806. [CrossRef] [PubMed]

17. Roger, E.; Lagarce, F.; Benoit, J. Development and Characterization of a Novel Lipid Nanocapsule Formulation of Sn38 for Oral Administration. Eur. J. Pharm. Biopharm. 2011, 79, 181-188. [CrossRef]

18. Sahoo, H. Förster resonance energy transfer-A spectroscopic nanoruler: Principle and applications. J. Photochem. Photobiol. C Photochem. Rev. 2011, 12, 20-30. [CrossRef]

19. Wallace, B.; Atzberger, P.J. Förster resonance energy transfer: Role of diffusion of fluorophore orientation and separation in observed shifts of FRET efficiency. PLoS ONE 2017, 12, e0177122. [CrossRef]

20. Lagarce, F.; Groo, A.-C.; Saulnier, P.; Gimel, J.-C.; Gravier, J.; Ailhas, C.; Benoit, J.-P. Fate of paclitaxel lipid nanocapsules in intestinal mucus in view of their oral delivery. Int. J. Nanomed. 2013, 8, 4291-4302. [CrossRef]

21. Roger, E.; Gimel, J.-C.; Bensley, C.; Klymchenko, A.S.; Benoit, J.-P. Lipid nanocapsules maintain full integrity after crossing a human intestinal epithelium model. J. Control. Release 2017, 253, 11-18. [CrossRef]

22. Billat, P.-A.; Roger, E.; Faure, S.; Lagarce, F. Models for drug absorption from the small intestine: Where are we and where are we going? Drug Discov. Today 2017, 22, 761-775. [CrossRef] [PubMed]

23. Hidalgo, I.J.; Raub, T.J.; Borchardt, R.T. Characterization of the Human Colon Carcinoma Cell Line (Caco-2) as a Model System for Intestinal Epithelial Permeability. Gastroenterology 1989, 96, 736-749. [CrossRef]

24. Han, C.; Wang, B. Factors That Impact the Developability of Drug Candidates; Wiley: Hoboken, NJ, USA, 2016; ISBN 9781118833322.

25. Van Breemen, R.B.; Li, Y. Caco-2 cell permeability assays to measure drug absorption. Expert Opin. Drug Metab. Toxicol. 2005, 1, 175-185. [CrossRef]

26. Rinaki, E.; Valsami, G.; Macheras, P. Classification System: The Central Role of Dose/Solubility Ratio. Pharm. Res. 2003, 20, 1917-1925. [CrossRef]

27. The International Council for Harmonisation of Technical Requirements for Pharmaceuticals for Human Use ICH Harmonised Guideline. Biopharmaceutics Classification System-Based Biowaivers. M9. Available online: https://database.ich.org/sites/ default/files/M9_Guideline_Step4_2019_1116.pdf (accessed on 16 April 2021).

28. Amidon, G.L.; Lennernäs, H.; Shah, V.P.; Crison, J.R. A Theoretical Basis for a Biopharmaceutic Drug Classification: The Correlation of in Vitro Drug Product Dissolution and in Vivo Bioavailability. Pharm. Res. Off. J. Am. Assoc. Pharm. Sci. 1995, 12, 413-420.

29. Costa, J.; Ahluwalia, A. Advances and Current Challenges in Intestinal in Vitro Model Engineering: A Digest. Front. Bioeng. Biotechnol. 2019, 7, 1-14. [CrossRef]

30. Beloqui, A.; Brayden, D.J.; Artursson, P.; Préat, V.; Des Rieux, A. A Human Intestinal M-Cell-like Model for Investigating Particle, Antigen and Microorganism Translocation. Nat. Protoc. 2017, 12, 1387-1399. [CrossRef]

31. Spadoni, I.; Zagato, E.; Bertocchi, A.; Paolinelli, R.; Hot, E.; Di Sabatino, A.; Caprioli, F.; Bottiglieri, L.; Oldani, A.; Viale, G.; et al. A Gut-Vascular Barrier Controls the Systemic Dissemination of Bacteria. Science 2015, 350, 830-835. [CrossRef] [PubMed]

32. Sorribas, M.; de Gottardi, A.; Moghadamrad, S.; Hassan, M.; Spadoni, I.; Rescigno, M.; Wiest, R. Isoproterenol Disrupts Intestinal Barriers Activating Gut-Liver-Axis: Effects on Intestinal Mucus and Vascular Barrier as Entry Sites. Digestion 2020, 101, 717-729. [CrossRef] [PubMed]

33. Ungaro, F.; Tacconi, C.; D'Alessio, S. Beyond Intestinal Barrier: The Blood Endothelium as a Second Wall of Defense Against Bacterial Invasion. Gastroenterology 2016, 150, 1678-1680. [CrossRef]

34. Deshmukh, R.; Bandyopadhyay, N.; Abed, S.N.; Bandopadhyay, S.; Pal, Y.; Deb, P.K. Strategies for Pulmonary Delivery of Drugs; Elsevier: Amsterdam, The Netherlands, 2019; ISBN 9780128145081.

35. Kasper, J.Y.; Hermanns, M.I.; Cavelius, C.; Kraegeloh, A.; Jung, T.; Danzebrink, R.; Unger, R.E.; Kirkpatrick, C.J. The Role of the Intestinal Microvasculature in Inflammatory Bowel Disease: Studies with a Modified Caco-2 Model Including Endothelial Cells Resembling the Intestinal Barrier in Vitro. Int. J. Nanomed. 2016, 11, 6353-6364. [CrossRef]

36. Hubatsch, I.; Ragnarsson, E.G.E.; Artursson, P. Determination of Drug Permeability and Prediction of Drug Absorption in Caco-2 Monolayers. Nat. Protoc. 2007, 2, 2111-2119. [CrossRef]

37. Kilin, V.N.; Anton, H.; Anton, N.; Steed, E.; Vermot, J.; Vandamme, T.F.; Mely, Y.; Klymchenko, A.S. Counterion-Enhanced Cyanine Dye Loading into Lipid Nano-Droplets for Single-Particle Tracking in Zebrafish. Biomaterials 2014, 35, 4950-4957. [CrossRef]

38. Young, B.; O'Dowd, G.; Woodford, P. Membrane Specialisations of Epithelia. In Wheater's Functional Histology: A Text and Colour Atlas; Churchill Livingstone: London, UK, 2013; pp. 88-91. ISBN 9780702047473.

39. Briske-Anderson, M.J.; Finley, J.W.; Newman, S.M. The Influence of Culture Time and Passage Number on the Morphological and Physiological Development of Caco-2 Cells. Proc. Soc. Exp. Biol. Med. 1997, 214, 248-257. [CrossRef] [PubMed]

40. Ma, T.Y.; Hollander, D.; Tran, L.T.; Nguyen, D.; Hoa, N.; Bhalla, D. Cytoskeletal Regulation of Caco-2 Intestinal Monolayer Paracellular Permeability. J. Cell. Physiol. 1995, 164, 533-545. [CrossRef] [PubMed]

41. Young, B.; O'Dowd, G.; Woodford, P. The microcirculation. In Wheater's Functional Histology: A Text and Colour Atlas; Churchill Livingstone: London, UK, 2013; pp. 150-153. ISBN 9780702047473. 
42. Rüffer, C.; Strey, A.; Janning, A.; Kim, K.S.; Gerke, V. Cell-Cell Junctions of Dermal Microvascular Endothelial Cells Contain Tight and Adherens Junction Proteins in Spatial Proximity. Biochemistry 2004, 43, 5360-5369. [CrossRef] [PubMed]

43. Hilgendorf, C.; Spahn-Langguth, H.; Regårdh, C.G.; Lipka, E.; Amidon, G.L.; Langguth, P. Caco-2 versus Caco-2/HT29-MTX Co-Cultured Cell Lines: Permeabilities via Diffusion, inside- and Outside-Directed Carrier-Mediated Transport. J. Pharm. Sci. 2000, 89, 63-75. [CrossRef]

44. Artursson, P.; Karlsson, J. Correlation between Oral Drug Absorption in Humans and Apparent Drug Permeability Coefficients in Human Intestinal Epithelial (Caco-2) Cells. Biochem. Biophys. Res. Commun. 1991, 175, 880-885. [CrossRef]

45. Aungst, B.J.; Nguyen, N.H.; Bulgarelli, J.P.; Oates-lenz, K. The Influence of Donor and Reservoir Additives on Caco-2 Permeability and Secretory Transport of HIV Protease Inhibitors and Other Lipophilic Compounds. Pharm. Res. 2000, 17, 1-5. [CrossRef]

46. Jung, S.J.; Choi, S.O.; Um, S.Y.; Kim, J.I.; Choo, H.Y.P.; Choi, S.Y.; Chung, S.Y.; Youn, S. Prediction of the Permeability of Drugs through Study on Quantitative Structure-Permeability Relationship. J. Pharm. Biomed. Anal. 2006, 41, 469-475. [CrossRef] [PubMed]

47. Artursson, P.; Magnusson, C. Epithelial Transport of Drugs in Cell Culture. II: Effect of Extracel I u Lar Calcium Concent Rat Ion on the Paracel I u Lar Transport of Drugs of Different Lipophilicities across Monolayers of Intestinal Epithelial (Caco-2) Cells. J. Pharm. Sci. 1990, 79, 595-600. [CrossRef] [PubMed]

48. Artursson, P. Epithelial Transport of Drugs in Cell Culture. I: A Model for Studying the Passive Diffusion of Drugs over Intestinal. J. Pharm. Sci. 1990, 79, 476-482. [CrossRef] [PubMed]

49. Volpe, D.A.; Faustino, P.J.; Ciavarella, A.B.; Asafu-Adjaye, E.B.; Ellison, C.D.; Yu, L.X.; Hussain, A.S. Classification of Drug Permeability with a Caco-2 Cell Monolayer Assay. Clin. Res. Regul. Aff. 2007, 24, 39-47. [CrossRef]

50. Roger, E.; Lagarce, F.; Garcion, E.; Benoit, J.P. Biopharmaceutical Parameters to Consider in Order to Alter the Fate of Nanocarriers after Oral Delivery. Nanomedicine 2010, 5, 287-306. [CrossRef]

51. Groo, A.C.; Bossiere, M.; Trichard, L.; Legras, P.; Benoit, J.P.; Lagarce, F. In Vivo Evaluation of Paclitaxel-Loaded Lipid Nanocapsules after Intravenous and Oral Administration on Resistant Tumor. Nanomedicine 2015, 10, 589-601. [CrossRef]

52. Mccann, J.J.; Choi, U.B.; Zheng, L.; Weninger, K.; Bowen, M.E. Optimizing Methods to Recover Absolute FRET Efficiency from Immobilized Single Molecules. Biophys. J. 2010, 99, 961-970. [CrossRef]

53. Nir, E.; Michalet, X.; Hamadani, K.M.; Laurence, T.A.; Neuhauser, D. Shot-Noise Limited Single-Molecule FRET Histograms: Comparison between Theory and Experiments. J. Phys. Chem. 2006, 110, 22103-22124. [CrossRef]

54. Bannunah, A.M.; Vllasaliu, D.; Lord, J.; Stolnik, S. Mechanisms of Nanoparticle Internalization and Transport Across an Intestinal Epithelial Cell Model: E Ff Ect of Size and Surface Charge. Mol. Pharm. 2014, 11, 4363-4373. [CrossRef]

55. Hua, S.; Marks, E.; Schneider, J.J.; Keely, S. Advances in Oral Nano-Delivery Systems for Colon Targeted Drug Delivery in Inflammatory Bowel Disease: Selective Targeting to Diseased versus Healthy Tissue. Nanomed. Nanotechnol. Biol. Med. 2015, 11, 1117-1132. [CrossRef]

56. Furst, T.; Dakwar, G.R.; Zagato, E.; Lechanteur, A.; Remaut, K.; Evrard, B.; Braeckmans, K.; Piel, G. Freeze-Dried Mucoadhesive Polymeric System Containing Pegylated Lipoplexes: Towards a Vaginal Sustained Released System for SiRNA. J. Controll. Rel. 2016, 236, 68-78. [CrossRef] [PubMed]

57. Paillard, A.; Hindré, F.; Vignes-colombeix, C.; Benoit, J.; Garcion, E. The Importance of Endo-Lysosomal Escape with Lipid Nanocapsules for Drug Subcellular Bioavailability. Biomaterials 2010, 31, 7542-7554. [CrossRef] [PubMed]

58. Garcion, E.; Lamprecht, A.; Paillard, A.; Aubert-Pouessel, A.; Menei, P.; Beno1, J. A New Generation of Anticancer, Drug-Loaded, Colloidal Vectors Reverses Multidrug Resistance in Glioma and Reduces Tumor Progression in Rats. Mol. Cancer Ther. 2006, 5, 1710-1723. [CrossRef] [PubMed]

59. Hamelers, I.H.L.; Staffhorst, R.W.H.M.; Voortman, J.; De Kruijff, B.; Reedijk, J.; Van Bergen, P.M.P.; Kroon, A.I.P.M. De Cancer Therapy: Preclinical High Cytotoxicity of Cisplatin Nanocapsules in Ovarian Carcinoma Cells Depends on Uptake by CaveolaeMediated Endocytosis. Clin. Cancer Res. 2009, 15, 1259-1269. [CrossRef] [PubMed] 